\title{
Insularity and economies of density: analyzing the efficiency of a logistic network using an econometric simulation-based approach
}

\section{Luisanna Cocco, Manuela Deidda, Michele Marchesi \& Francesco Pigliaru}

To cite this article: Luisanna Cocco, Manuela Deidda, Michele Marchesi \& Francesco Pigliaru (2018): Insularity and economies of density: analyzing the efficiency of a logistic network using an econometric simulation-based approach, Regional Studies, DOI: 10.1080/00343404.2018.1490500

To link to this article: https://doi.org/10.1080/00343404.2018.1490500

+ View supplementary material $匚$

曲 Published online: 26 Jul 2018.

Submit your article to this journal $\pi$

凹 Article views: 20

View Crossmark data \ulcorner 


\title{
Insularity and economies of density: analyzing the efficiency of a logistic network using an econometric simulation-based approach
}

\author{
${\text { Luisanna } \operatorname{Cocco}^{\mathbf{a}} \odot \text {, Manuela Deidda }}^{\mathbf{b}} \odot$, Michele Marchesi ${ }^{\mathrm{c}} \odot$ and \\ Francesco Pigliaru ${ }^{d}$
}

\begin{abstract}
This paper explores the challenges posed by insularity to economic development and overall welfare from a novel viewpoint. Using a multidisciplinary approach, we investigated the additional burden that this permanent geographical condition poses to retailers whose profit-maximizing strategy relies upon the exploitation of the economies of density. The analysis results show that a retailer finds it convenient to develop its network on the mainland, exploiting the proximity of his stores and distribution centres. Further, it shows that insularity, an unlikely similar condition such as peripherality and remoteness, prevents retailers from expanding their network on an island, thus lowering competition and affecting consumers' welfare.
\end{abstract}

KEYWORDS

insularity; economies of density; retail sector; simulation

JEL C63, L10, L81, R12

HISTORY Received 1 March 2016; in revised form 25 April 2018

\section{INTRODUCTION}

The underperformance of the European Union's (EU) islands as regards the EU average ${ }^{1}$ has motivated a significant policy and economic debate on the peculiarity of island economies with respect to both the mainland and the peripheral regions.

Researchers and policy-makers have indeed recognized that, despite a substantial degree of heterogeneity among these islands, ${ }^{2}$ they all share peculiar characteristics and face specific challenges that make them fall behind the $\mathrm{EU}$ and the national goals for sustainable economic development (European Observation Network for Territorial Development and Cohesion (ESPON), 2010).

Insularity is a 'permanent phenomenon of physical discontinuity' (European Small Islands Federation (Eurisles), 2002) characterized by permanent geographical characteristics such as remoteness, smallness and vulnerability that affect the islands' attractiveness, leading to an unfavourable environment for capital and the workforce which is likely to adversely affect their development in the long run.

Remoteness hinders accessibility, i.e., the opportunity to reach spatially distributed markets, which is interconnected to both the transportation network and the proximity to central hubs. As emphasized by a wide strand of the literature, accessibility affects localization choices (central areas are more accessible from national and international networks) and spatial interactions. ${ }^{3}$ Furthermore, the discontinuity characterizing islands worsens the increased transport costs associated with remoteness, making islands strongly dependent from more expensive sea and air transport. Thus, remoteness diminishes production efficiency, which is one key determinant of competitiveness in an increasingly interconnected global market.

Smallness leads to relatively higher input prices with respect to non-insular territories because of a low domestic

\section{CONTACT}

a (Corresponding author) luisanna.cocco@diee.unica.it

Department of Electric and Electronic Engineering, University of Cagliari, Cagliari, Italy.

${ }^{\mathbf{b}}$ manuela.deidda@crenos.unica.it

Health Economics and Health Technology Assessment, Institute of Health \& Wellbeing, Glasgow, UK; Centre for North South Economic Research (CRENoS), Cagliari, Italy.

'@ michele@diee.unica.it

Department of Mathematics and Computer Science, University of Cagliari, Cagliari, Italy.

d@pigliaru@unica.it

Department of Law, University of Cagliari, Cagliari, Italy.

(-) Supplemental data for this article can be accessed http://dx.doi.org/10.1080/00343404.2018.1490500. 
demand. ${ }^{4}$ Furthermore, the islands' vulnerability and the geographical peculiarities of islands make them strictly dependent on a single economic activity (e.g., tourism, fishing or farming) so that they may not be able to react promptly and effectively to potential shocks caused by recessions and demand contractions in those specific sectors (Zagari, 2011).

Note that it is the joint and reinforcing effect of smallness, discontinuity and remoteness that characterizes the islands' 'bad geography'. We might observe territories that are peripheral areas characterized by remoteness and discontinuity (e.g., Sweden) or insular territories that are neither remote nor small (e.g., UK). The challenges faced by these territories are less severe than those faced by the islands.

Being a 'permanent phenomenon of physical discontinuity' (Eurisles, 2002), insularity cannot be eliminated, while policy interventions might only reduce the islands' economic backwardness.

In that regard, while policy-makers have put a considerable effort into the development of appropriate policies to offset the geographical disadvantage connected to insularity, the contribution of the literature on the causes of the islands' economic disadvantage is instead relatively scant. ${ }^{5}$ Most importantly, insularity has rarely been disentangled from conditions such as smallness and peripherality, thus making it difficult to identify the additional specific burden sustained by the islands compared with that sustained by regions that are similar to islands for some characteristics (i.e., smallness, peripherality, remoteness), but which are connected to the mainland.

This paper investigates the additional costs of insularity under a novel and effective viewpoint, disentangling insularity from similar conditions, such as smallness and peripherality, and identifying the additional specific burden sustained by the islands. It investigates the role of the land discontinuity implied by insularity in the development of a contiguous store network for retailers whose profitmaximizing strategy relies on the exploitation of economies of density. Specifically, the role of insularity is investigated in the Italian context, while analyzing the hypothetical diffusion of an Italian retail chain, Esselunga, in almost the entire Italian territory.

Italy and Esselunga represent a very interesting case study. Italy allows the proper exploration of the additional burden posed by insularity in relation to the areas characterized by similar disadvantages such as peripherality and smallness - but not representing disconnected nodes in a hypothetical profit-maximizing distribution network that relies on economies of density. Indeed, the Italian territory spreads from north to south, thus allowing the role of peripheral areas to be taken into account.

Moreover, it includes two islands, Sicily and Sardinia: the former is densely populated and close to the mainland whereas the latter is characterized by low population density and remoteness. Esselunga is the fourth largest retailer in Italy. To date, it has opened stores in only six Northern Italian regions and does not stock the merchandise in warehouses, but uses distribution centres, which are distributed in the area where it operates. Its distribution strategy makes this retailer a good candidate for the case study. ${ }^{6}$

In order to investigate the additional burden posed by insularity, we started designing a hypothetical network of stores and distribution centres. We selected 130 Italian municipalities and designed to place in each of them a hypothetical store or a hypothetical distribution centre, thus setting the locations of stores and centres. For the distribution centres we also set their opening date in order to design a contiguous network. Indeed, for a retailer exploiting the economies of density, cost saving is achieved through the spatial proximity of stores and distribution centres. Creating a contiguous store network and maintaining a high store density leads to lower distribution costs that compensate for the sales cannibalization that arises from placing new stores next to existing ones. In such a network, placing new stores on an island implies a 'jump' (i.e., a discontinuity in the network), such that a distribution centre on an island cannot serve stores located outside the island, while on in mainland region the same distribution centre serves other regions as well, spreading its net benefits among a larger number of stores. In this regard, insularity poses an additional burden with respect to the mere logistic problem caused by distance.

In order to build the designed hypothetical network, we first estimated some cost parameters and developed a demand model that allowed the effects of distance and those of the different locations, such as urban locations and rural or non-urban locations to be taken into account (see Appendix B, and specifically Table B2, in the supplemental data online). We then solved a profit-maximization problem, i.e., Esselunga's profit-maximization problem, whose solution is the opening date of the hypothetical stores (see equation 4 below).

The paper is organized as follows. The next section provides a brief literature review. The third section describes the model, specifically: the hypothetical network and the underlying assumptions of the model; the costs; Esselunga's maximization problem; and the methodology used to measure the economies of density. The fourth section presents the results for Esselunga's hypothetical network: the solution of the problem; the measure of economies of density for the hypothetical network; and the effects accountable for insularity and peripherality. The fifth section discusses the limitations of the model, makes conclusions and presents some final policy considerations. Further details are provided in the supplemental data online: Appendices A and B give an overview of Esselunga, its store network and an estimation of the demand model; Appendix $\mathrm{C}$ illustrates the results obtained by applying the approach described in the fourth section to the real Esselunga network; and Appendix D details of the hypothetical network calibration and the data used in the analysis.

\section{LITERATURE REVIEW}

In Europe, the policy debate regarding insularity started more than 20 years ago when the Amsterdam Treaty (art. 
158) and the Treaty of Maastricht (art. 154) focused on the necessity to develop appropriate policies assuring the islands a level of development homogeneous with the mainland, thus offsetting the geographical disadvantage connected to insularity. The policy relevance of the economic challenges faced by the island economies has fostered a wide strand of empirical and theoretical contributions to the economic literature, aiming to investigate the causes of the islands' economic disadvantage.

Theoretical models analyze the effect of the distinctive features of insularity on economic development. The Trade Gravity Model considers the detrimental effect of remoteness on trade; contributions to the New Economic Geography focus on the joint effect of distance and smallness respectively, affecting both the returns to scale and the trades, on the choice of firm localization; the New Trade Theory assesses the economies of scale's key role and the network effects on trade. ${ }^{7}$ However, to the best of our knowledge, the joint effect of island characteristics (smallness, remoteness and vulnerability) and, thus, the specificity of insularity have never been tackled. On the other hand, empirical papers provide conflicting results on the impact of insularity on economic growth (Deidda, 2016). ${ }^{8}$

Furthermore, insularity has rarely been disentangled from similar conditions such as smallness and peripherality, thus making it difficult to identify the additional specific burden sustained by the islands with respect to that sustained by regions which are similar to the islands as regards some characteristics (i.e., smallness, peripherality, remoteness), but which are connected to the mainland. This paper attempts to fill these gaps in the literature by investigating how the land discontinuity, implied by insularity, impacts retailers' profits, and hence the development of a store network, considering retailers who exploit the economies of density and decide to place stores also on an island. In this regard, it should be highlighted that geography is crucial in determining the effectiveness of a strategy based on the economies of density. From this point of view, bad geography, in terms of remoteness and peripherality, increases transport costs, thus preventing the economies of density from being properly exploited. As Holmes (2011) and Holmes and Lee (2012) point out, the economies of density cannot be disentangled from geography, since what matters is not only increasing the number of stores in a network (i.e., economies of scale) but also their location.

A wide strand of the theoretical literature has emphasized the key role played by geography for the retail sector. ${ }^{9}$ Christaller (1933) and Lösch (1944) explain the size, nature and spacing of cities, considering them as central places that supply goods to the surrounding population. In particular, retailing activities are located in central markets, and the likelihood of demanding goods or services provided in these central places will decrease with distance. Furthermore, only consumers located within a certain range will reach each store; the competitors will serve consumers located beyond that range. Further contributions analyze the heterogeneity among goods (O'Kelly, 1981; Thill \& Thomas, 1987). The retail gravitational theory, originally formulated by Reilly, and further empirically developed by Converse (1943), Reilly (1953) and Rouse (1953, pp. 1-5), claimed that the size of trade between two cities and an intermediate town increases with the population of the cities and decreases with the square of the distances between the cities. While recognizing its theoretical validity, empirical application raised the need to tackle consumer heterogeneity, and thus to consider socioeconomic factors, accessibility and the heterogeneity among retailing activities affecting the retailers' profits.

Given the economic challenges faced by the islands, investigating to what extent insularity represents a threat for retailers exploiting the economies of density holds its own interest. In this regard, the well-known US retailer Walmart, representing a giant in the American retail industry, can maximize its profits, offer lower prices and increase consumers' welfare thanks to the exploitation of the economies of density. In fact, Walmart opened new stores close to both existing ones and distribution centres, creating a contiguous retail network which radiates from the inside out. ${ }^{10}$

Even if Walmart's success has been imputed to several sources (the function of retail production, economies of density, the investment in information technology, management contiguity) (Basker, 2005; Basker \& Noel, 2009; Cleary \& Lopez, 2008; Ellickson \& Grieco, 2013; Hausman \& Leibtag, 2005; Hausman \& Leibtag, 2007; Neumark, Zhang, \& Ciccarella, 2008), exploiting the economies of density plays a key role, as claimed by Holmes (2011) who shows that following such a strategy is the best possible choice. Particularly, Holmes emphasized that the cost reduction achieved by saving in transport costs remarkably compensates for the losses derived by cannibalization, thus allowing Walmart to achieve the maximum possible profits.

\section{THE PROPOSED MODEL}

The following sections will describe the hypothetical network built to solve the Esselunga profit-maximization problem, starting from the number, location and opening date of the existing Esselunga stores and distribution centres.

\section{Hypothetical network}

In symmetry with the real network, we studied the hypothetical future diffusion of Esselunga over a span of over 33 years, from 1 January 2013 to 31 December 2045. We selected 130 Italian municipalities and assumed that each contains either a hypothetical store or a hypothetical distribution centre. Specifically, we hypothesized the opening of 127 stores and three distribution centres (see Appendix D in the supplemental data online for more details).

Figure 1 shows the real and hypothetical Esselunga network. The real Esselunga network is represented by the large/grey circles and small/black circles which indicate the distribution centres and the stores respectively. Instead, the hypothetical Esselunga network is represented by large/ white circles and small/grey circles that indicate the distribution centres and the stores respectively. 


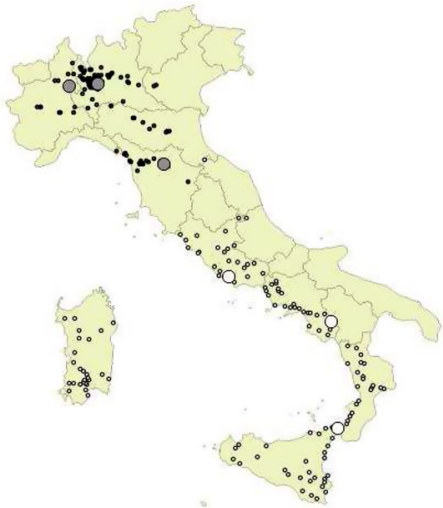

Figure 1. Real Esselunga network (large/grey circles and small/ black circles) and the hypothetical Esselunga network (large/ white circles and small/grey circles).

We assumed Esselunga opening hypothetical stores in Calabria, Campania, Lazio, Sardinia and Sicily, and for each store we chose a location, i.e., the municipality where it is located. As for the distribution centres, we assumed Esselunga opening hypothetical distribution centres only in three regions: Calabria, Lazio and Sicily.

For the hypothetical distribution centres, in addition to the location we also chose their opening date to allow for contiguity with the real network. Consequently, we assumed that the first distribution centre opens in Lazio in 2020, the second in Campania in 2027 and the third in Sicily in 2035. Note that setting the opening date of the distribution centres allows a contiguous network to be built. Hence, the location, as well as the opening dates of the distribution centres, play a key role in allowing the exploitation of economies of density, and as in Holmes (2011), the profit-maximization problem is solved with respect to the opening sequence of hypothetical stores.

Starting from the hypothetical network described above, the problem to be solved (the Esselunga problem) is finding the sequence of hypothetical stores to be opened each year in order to maximize its profits. The adopted procedure is described in detail below, starting from the identification of the fixed and variable costs involved in the definition of the Esselunga problem.

\section{Fixed and variable costs}

In not having access either to confidential data on Esselunga's logistic costs or to the cost components at a store level, we estimated these costs using the approach suggested by Holmes (2011).

First, we defined the distribution costs as a linear function of distance ${ }^{11}$ as follows:

$$
C_{j}^{d}(t)=\tau d_{j}(t)
$$

where $\tau$ is the cost per kilometre per year of servicing the store $j$, assuming a single delivery run from the distribution centre to each store every day, as Esselunga does; and $d_{j}(t)$ is the distance $(\mathrm{km})$ from store $j$ to the closest distribution centre opened at time $t$.
Distribution costs are fixed; therefore, they do not vary with the sales volume.

Consider the variable costs. Labour costs, $C_{j}^{\mathrm{lab}}$, vary with the sales volume and are defined as:

$$
C_{j}^{\mathrm{lab}}(t)=v^{\mathrm{Labor}} * R_{j}(t)
$$

where $\nu^{\text {Labor }}$ is the labour cost coefficient of proportionality; and $R_{j}(t)$ is the revenue of store $j$ at time $t$. Intuitively, the larger the sales volume at a store $j$, the larger the number of workers and thus the labour cost.

Finally, the amortization costs, $C_{j}^{\mathrm{am}},{ }^{12}$ are defined by:

$$
C_{j}^{\mathrm{am}}(t)=v^{\mathrm{Am}} R_{j}(t)
$$

where $v^{A m}$ is the amortization cost coefficient of proportionality. The larger the sales volume at a store $j$, the greater the parking lot and the required space, and consequently the amortization costs. Appendix B in the supplemental data online explains how the parameters $\tau, \nu^{\text {Labor }}$ and $\nu^{\text {Am }}$ and the variable $d_{j}$ were computed.

\section{The Esselunga problem}

The Esselunga problem is a maximization problem whose solution involves the profit-maximizing hypothetical store opening sequences (i.e., opening dates). Formally, it is defined as:

$$
\begin{aligned}
& \sum_{t=T_{I, R}}^{t=T_{H}} \sum_{j \in B_{t}^{E s s}}\left[\mu R_{j}(t)-\left(C_{j}^{\mathrm{lab}}(t)+C_{j}^{\mathrm{am}}(t)+C_{j}^{d}(t)\right)\right] \\
& +\max _{a} \sum_{t=T_{I, H}}^{t=T_{H}} \sum_{j \in B_{t}^{E s s}}\left[\mu R_{j}(t)-\left(C_{j}^{\mathrm{lab}}(t)+C_{j}^{\mathrm{am}}(t)+C_{j}^{d}(t)\right)\right]
\end{aligned}
$$

where $a$ is the opening sequence, including the set of stores opened in each period $t ; T_{I, R}$ is the initial time - it is the time during which Esselunga starts its real expansion, set as 1980; $T_{I, H}$ and $T_{H}$ indicate the beginning and end of the Esselunga hypothetical diffusion - the diffusion goes from $T_{I, H}=2013$ to $T_{H}=2045 ; B_{t}^{E s s}$ represents the set of the Esselunga stores present in the market at time $t$; $\mu R_{j}(t)$ is the gross margin of store $j$ before accounting for distribution, amortizations, labour costs and taxes at time $t$; and

$$
R_{j}(t)=\sum_{l \mid l \in r_{j}, \text { dist }_{j l}<30, t_{O, j}<t_{0, j^{\prime} \in l}} \lambda_{l}(t) * p_{j, l}(t) * n_{l}(t)
$$

is the revenue of the store $j$ at time $t$ to which the consumers of locations $l$ can contribute. Following the approach of Holmes (2011), we assumed that all consumers of the generic location $l$, that is, $<30 \mathrm{~km}^{13}$ from store $j^{14}$ and which is located in the region, $r_{j}$, of store $j$, can be potential consumers of store $j$ when store $j^{\prime}$ located in their municipality $l$ is closed: ${ }^{15} \lambda_{l}$ represents the average spending per consumer; $p_{j, l}$ is the probability that a consumer located in municipality $l$ buys from Esselunga store $j^{16}-$ it is calculated using the demand model ${ }^{17}$ (see Appendix B in 
the supplemental data online); $n_{l}$ is the number of potential consumers at location $l$; and

$$
\mu R_{j}(t)-\left[C_{j}^{\mathrm{lab}}(t)+C_{j}^{\mathrm{am}}(t)\right]
$$

is operating profits.

The solution to the Esselunga problem is one of the possible profit-maximizing hypothetical store-opening sequences. This is because, given the enormous number of possible combinations of hypothetical store-opening sequences, the model chooses the sequence of regions that assure the maximum profit, among all the possible sequences of regions where, year by year, Esselunga can open its hypothetical new stores, and not the sequence of stores that assure the maximum profit.

Specifically, given a region to which a precise number of stores is associated, the model computes the potential profit associated with that region, selecting the new stores to be opened at random and then computing a potential profit for each selected store. We ran several simulations with the same initial conditions but different seeds of the random number generator. Overall, all the performed simulations presented a consistent behaviour, and we always picked out sequences of regions that were identical to those described below. As a result, the solution to the Esselunga problem is one of the possible profit-maximizing hypothetical store-opening sequences, but providing the sequence of regions that assure the maximum profit.

According to what happens in reality, the model assumes that the stores placed in Tuscany and Liguria refer to the distribution centre in Tuscany, whereas all the remaining stores (real and hypothetical ones) refer to the nearest distribution centre. We assumed that each year four stores are opened, and once a store or a distribution centre is opened, it will never be closed.

The formulation of the Esselunga problem accounts for market size, the distance between stores and distribution centres, and the cannibalization phenomenon. Specifically, for each Italian region we estimated the market size, $\lambda_{l}(t) * n_{l}(t)$, using the demand model (see Appendix B in the supplemental data online for the details) and distribution costs, $C_{j}^{d}(t)$, knowing the distance, $d_{j}(t)$, between stores and distribution centres (see Appendix D in the supplemental data online for the details about this distance).

We took the cannibalization phenomenon into account through the probability, $p_{j, l}(t)$, that, in turn, as a result of the demand model, depends on the distance, dist ${ }_{l j}$, between the locations of potential consumers, $l$, and the location, $j$, where the stores are placed. We assumed that each consumer at location $l$ can be a potential consumer of every Esselunga store located at $<30 \mathrm{~km}$ if there is not any Esselunga store in this location (see the definition of revenue equation 5). Consequently, as the network increases, the number of potential consumers, $n_{l}(t)$, of each Esselunga store decreases. ${ }^{18}$

\section{A measure of the economies of density}

Economies of density lead to a reduction in the average distance between stores and distribution centres, and hence in the distribution costs. However, the benefits of cost savings will reduce the operating profits of the existing stores due to a cannibalization effect. If economies of density are in place, there will be a substantial reduction in the distribution costs and this will have to compensate fully for the reduction of the operating profits.

To verify if this compensation exists in the proposed model, and hence to verify if the network built by the model follows the economies of density, we applied the approach of Holmes (2011), as described below.

We divided the stores of the hypothetical network into three groups, $g_{1}, g_{2}$ and $g_{3}$, where each group of stores, $g_{h}$, is defined by the Esselunga age at the opening time, age . Specifically, age $e_{o}$ is defined as the number of years that Esselunga has been in a region since the first opening in that region. According to this definition, the first group includes the first stores in their respective regions, opened when Esselunga had been in these regions for no more than two years. The second group includes the stores opened when Esselunga had already been in these regions for between three and five years. Finally, the third group contains the stores in their respective regions, opened when Esselunga had been in these regions for more than five years.

We first computed the number of stores, $N$, for each group $g_{b}$. For each group of stores, $g_{b}$, we then split the stores in the group on the basis of the region, $r$, where the stores are placed obtaining the sets called $g_{h, r}$ in the following one. For each set $g_{h, r}$, we computed the average, across the store new openings, of incremental sales, $S_{I}$, operating profit, $P_{O}$, incremental distribution centre distance, $D$, stand-alone sales, $S_{I}^{S-A}$, and stand-alone operating profit, $P_{O}^{S-A}$. Finally, given the averages of these quantities for each region, we computed the regional average for each group $g_{b}$.

The incremental sales, $S_{I}$, and the operating profit, $P_{O}$, of all stores at each group, $g_{b}$, in their opening year, $t_{O}$, are computed according to:

$$
S_{I}=\frac{1}{N_{r}} \sum_{r=1}^{r=N_{r}}\left\{\frac{1}{N_{g_{b, r}}} \sum_{j \in g_{b, r}} R_{j}\left(t_{O}\right)\right\}
$$

$$
\begin{aligned}
P_{O} & =\frac{1}{N_{r}} \sum_{r=1}^{r=N_{r}} \\
& \times\left\{\frac{1}{N_{g_{b, r}}} \sum_{j \in g_{b, r}}\left[R_{j}\left(t_{O}\right)-\left(v^{\text {Labor }} * R_{j}\left(t_{O}\right)+v^{\mathrm{Am}} R_{j}\left(t_{O}\right)\right)\right]\right\}
\end{aligned}
$$

where $N_{g_{b, r}}$ is the total number of Esselunga stores in group $g_{b}$ and region $r ; N_{r}$ is the number of regions in group $g_{b}$; and $R_{j}$ is the revenues computed following equation (5). Namely, the incremental sales (operating profit) are what store $j$ adds to the total Esselunga sales (profit) in its opening year. 
The incremental distribution centre distance, $D$, is defined by:

$$
D=\frac{1}{N_{r}} \sum_{r=1}^{r=N_{r}}\left\{\frac{1}{N_{g_{h, r}}} \sum_{j \in g_{b, r}} \min _{i} D_{j}\left(t_{O}\right)\right\}
$$

where $\min _{i} D_{j}\left(t_{O}\right)$ is the distance of store $j$ from the nearest distribution centre opened at $t_{O}$.

Stand-alone sales, $S_{I}^{S-A}$, and stand-alone operating profit, $P_{O}^{S-A}$, of new store openings are defined as follows:

$$
\begin{gathered}
S_{I}^{S A}=\frac{1}{N_{r}} \sum_{r=1}^{r=N_{r}}\left\{\frac{1}{N_{g_{b, r}}} \sum_{j \in g_{b, r}} R_{j}^{S A}\left(t_{O}\right)\right\} \\
P_{O}^{S A}=\frac{1}{N_{r}} \sum_{r=1}^{r=N_{r}} \\
\times\left\{\frac{1}{N_{g_{b, r}}} \sum_{j \in g_{b, r}}\left[R_{j}^{S A}\left(t_{O}\right)-\left(v^{\mathrm{Labor}} * R_{j}^{S A}\left(t_{O}\right)+v^{\mathrm{Am}} R_{j}^{S A}\left(t_{O}\right)\right)\right]\right\}
\end{gathered}
$$

where the revenue, $R_{j}^{S A}$, is calculated using equation (5) assuming that the consumers distant from store $j<$ $30 \mathrm{~km}$ can also be potential consumers of store $j$ when the store located in their municipality is opened. Namely, they are defined as the sales (profits) that would be gained in a particular year for pre-existing stores in a region if no new stores were opened in that year and in that region.

\section{RESULTS}

\section{Esselunga problem resolution}

The Esselunga problem was implemented in Smalltalk language and run over a simulation period of 66 years, which is a simulation step equal to one year. Starting from 1980, the model simulates the diffusion of the Esselunga network all over the Italian territory solving Esselunga's problem, hence picking a sequence for a hypothetical profit-maximizing store opening, $a$ (see the third section and, in particular, equation 4).

The sequence of store openings, $a$, obtained with the simulation identifies a network that is strongly characterized by the economies of density (Table 1), and which spreads from north to south (Figures 2 and 3).

The opening sequence gives rise to a contiguous network, opening new stores first in Lazio, then in Campania, Calabria, Sicily and, lastly, Sardinia.

Starting from the real network, Figures 2 and 3 show the hypothetical Esselunga diffusion from 2013 to 2045. In the hypothetical network, the stores are closely packed together and Esselunga does not jump to a far-off region when it places new stores. It places its stores in a contiguous way, from Lazio to Sardinia, thus gaining higher profits thanks to the lower distribution costs. Sardinian stores are opened after 2034. They are the latter stores to be opened (Figure 3(b)) and hence their opening for Esselunga represents the least profitable choice.

Table 1. Incremental sales, $S_{\boldsymbol{I}}$, operating profit, $\boldsymbol{P}_{\boldsymbol{O}}$, incremental distribution centre distance, $\boldsymbol{D}$, stand-alone sales, $S_{\boldsymbol{I}}^{\boldsymbol{S}-\boldsymbol{A}}$, and stand-alone operating profit, $P_{O}^{S-A}$, of new store openings for the hypothetical scenario.

\begin{tabular}{lcccccc}
\hline & $\boldsymbol{N}$ & $\boldsymbol{S}_{\boldsymbol{I}}(€$ thousands) & $\boldsymbol{P}_{\boldsymbol{O}}(€$ thousands) & $\boldsymbol{D}(\mathbf{k m})$ & $\boldsymbol{S}_{\boldsymbol{I}}^{S-\boldsymbol{A}}(€$ thousands) & $\boldsymbol{P}_{\mathbf{O}}^{S-\boldsymbol{A}}(€$ thousands) \\
\hline All & 127 & 492.78 & 85.74 & 290.48 & 525.61 & 91.45 \\
$1 \leq$ Age $_{\mathrm{O}} \leq 2$ & 40 & 641.62 & 111.64 & 366.65 & 711.82 & 123.86 \\
$3 \leq$ Age $_{\mathrm{O}} \leq 5$ & 60 & 469.69 & 81.72 & 266.59 & 483.52 & 84.13 \\
Age $_{\mathrm{O}}>5$ & 27 & 277.28 & 48.25 & 239.64 & 285.93 & 49.75 \\
\hline
\end{tabular}

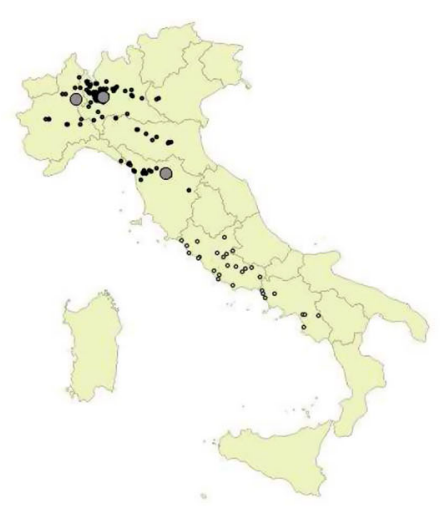

(a)

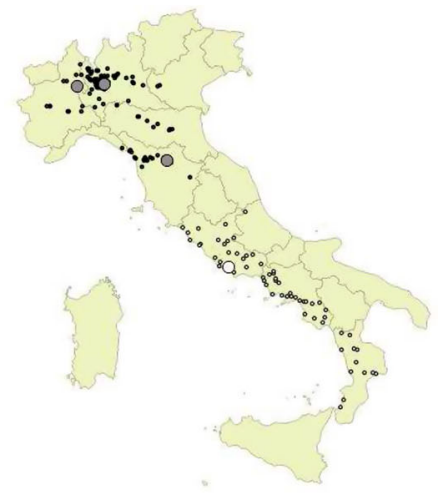

(b)

Figure 2. Stores opened between 1980 and 2019 (a) and between 1980 and 2026 (b) in a hypothetical scenario. 


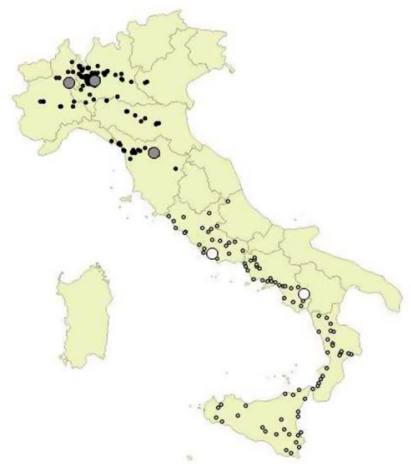

(a)

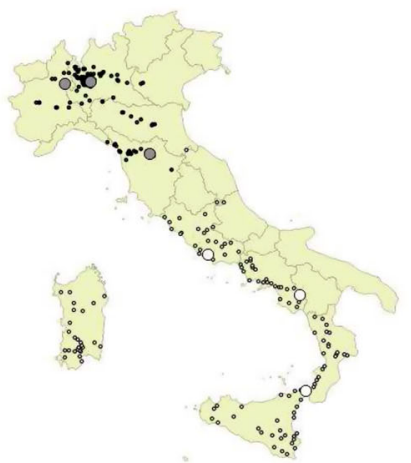

(b)

Figure 3. Stores opened between 1980 and 2034 (a) and between 1980 and 2045 (b) in a hypothetical scenario.

\section{Economies of density}

Given the opening sequence of the hypothetical stores, which is the solution to the Esselunga profit-maximization problem, we can apply the approach presented in the fourth section to evaluate if Esselunga follows the economies of density in its hypothetical future diffusion. ${ }^{19}$ Table 1 shows the number of stores, $N$, incremental sales, $S_{I}$, operating profit, $P_{O}$, incremental distribution centre distance, $D$, stand-alone sales, $S_{I}^{S-A}$, and stand-alone operating profit, $P_{O}^{S-A}$, of new store openings for this scenario.

We can see that, moving down the table to stores opening later in a region (i.e., as the store density in that region increases), both the operating profit, $P_{O}$, and the incremental distribution centre distance, $D$, decrease. Therefore, the stores that opened later deliver a lower operating profit, but since they are closer to a distribution centre they incur lower distribution costs. Since the second effect compensates for the first one, the Esselunga hypothetical network is characterized by economies of density. Indeed, moving from the first to the second group, there is a reduction in the operating profit of $€ 29,920$ and a reduction of the distribution costs of $€ 280,660$; moving from the second to the third group, there is a reduction of the operating profit of $€ 33,470$ and a reduction of the distribution costs of $€ 75,570$.

Note that there is a small difference between standalone and incremental sales, implying a small degree of market overlap with existing stores. Average stand-alone sales is $€ 490,000$ compared with an incremental value of $€ 490,000$, and a small degree of market overlap with existing stores emerges in each group. This small degree of market overlap can be explained by the chosen store configuration and by the small number of stores. Assuming that only one store is located in each municipality strongly affects the degree of market overlap. ${ }^{20}$ The real network instead shows a higher degree of market overlap (e.g., Milan has 26 stores) (see Appendix C in the supplemental data online).

\section{Insularity and peripherality effects}

The previous section suggested that the solution to the Esselunga problem allows one to demonstrate that the hypothetical Esselunga network being built closely follows the economies of density.

First, the results lead one to conclude that a retailer has always a higher convenience in placing new stores and distribution centres on the mainland first, rather than starting with new stores and distribution centres on the islands. Only when the market on the mainland is saturated will the retailer find it convenient to place new stores and distribution centres on an island. Therefore, the island may benefit from the opening of Esselunga stores in its territory only after some years. This implies that an island will exploit the added value related to this economic activity later compared with the mainland.

Second, the solution to the Esselunga problem allows one to quantify the effects of insularity on Esselunga's profits while Esselunga extends its store network. We performed a detailed analysis of the distances between the stores and the nearest distribution centre, and hence of the distribution costs, in order to investigate the additional costs of the insularity incurred by a retailer (Esselunga in the case study), which exploits the economies of density and wants to expand its network on an island (exactly in Sardinia in this analysis). Specifically, we evaluated the distribution costs in four different years: $t=2013,2020,2027$ and 2035. ${ }^{21}$

Table 2 shows the average distances, $\bar{D}$, between the stores and the nearest distribution centre in each region and the average distribution costs, $\bar{C}$, across all regions. Note that the opening of new distribution centres decreases $\bar{D}$ and $\bar{C}$ for all regions except Sardinia, as we move from the second to the fifth column (and hence while new distribution centres open over time). ${ }^{22}$ The average costs in 2035 across all regions, except Sardinia, are $€ 270,000$. Instead, in the same year, in Sardinia they are $€ 1.02$ million, showing that distribution costs on an island are substantially higher than those in peninsular regions. Consequently, in the case of a production strongly characterized by economies of density, distribution costs are permanently higher for an island. In this regards, insularity implies a discontinuity with respect to the stores on the mainland, thus breaking the distribution network and entailing higher distribution costs, even when all the planned openings of the distribution centres take place. 
Table 2. Average distances $(\mathrm{km}), \overline{\mathbf{D}}$, of the stores in a region from the nearest distribution centres and average distribution costs $(€$ millions), $\overline{\mathbf{C}}$, in each region over time.

\begin{tabular}{lccccc}
\hline Stores' region & & $\mathbf{2 0 1 3}$ & $\mathbf{2 0 2 0}$ & $\mathbf{2 0 2 7}$ & $\mathbf{2 0 3 5}$ \\
\hline Calabria & $\bar{D}$ & 678.065 & 392.385 & 162.612 & 92.980 \\
& $\bar{C}$ & 1.90 & 1.10 & 0.46 & 0.30 \\
Campania & $\bar{D}$ & 430.254 & 160.982 & 77.683 & 77.683 \\
& $\bar{C}$ & 1.20 & 0.45 & 0.22 & 0.22 \\
Lazio & $\bar{D}$ & 251.040 & 6.70 .782 & 69.782 & 69.782 \\
& $\bar{C}$ & 481.467 & 0.20 & 0.20 & 0.20 \\
Sardinia & $\bar{D}$ & 1.35 & 374.280 & 366.677 & 362.874 \\
& $\bar{C}$ & 758.739 & 1.05 & 1.03 & 1.02 \\
Sicily & $\bar{D}$ & 2.13 & 465.440 & 338.879 & 128.431 \\
& $\bar{C}$ & & 1.30 & 0.95 & 0.36 \\
\hline
\end{tabular}

Since we do not have access to confidential data on Esselunga's logistics costs, we hypothesized, as in Holmes (2011), that distribution costs are proportional to the distance, $d_{j}$, between the stores and the nearest distribution centre (see equation 1). In order to evaluate the distribution costs, we used the measure of the cost per kilometre, $\tau$, provided by Holmes. As a result, $\tau$ does not allow a strictly accurate estimation of the distribution costs, but offers only some insights about the magnitude orders of these costs.

Note that achieving a precise estimate of the distribution costs is beyond the purpose of this paper. The primary aim is to show that extending the network to an island is not an optimal choice, since the insularity condition does not allow one to create a dense network of stores and distribution centres. In this regard, finding that the average distance (and thus the average costs) decreases for peripheral regions as the network size increases, but it remains stable when the retailer expands the network on an island, responds to the key research question of this paper: that is, identifying the additional challenges faced by the islands compared with peripheral areas. Using retailer-specific distribution costs would increase the precision of the estimate, but it is unlikely to change the conclusions of this paper.

Further, the value of $\tau$ does not change in the case of Sardinia, and the distance, $d_{j}(t)$, from the Sardinian stores to the closest distribution centre opened is computed by hypothesizing a connection by land instead of a connection by sea (see Appendix B in the supplemental data online for details). Consequently, the $\tau$ used represents, to some extent, a lower bound of cost per kilometre, and our evaluation of transport cost might be downward biased. This is because different modes of transport are characterized by different trends, and the price index for sea transport is always higher than that for land transport. In addition, the choice about the most suitable modes of transport depends on both distance and the quantities being transported. For example, for distances between 500 and $700 \mathrm{~km}$, the most convenient mode of transport is by land (Confcommercio, 2014; Mazzarino, 1998). Our model deals with distances between stores and the distribution centres within this range. Considering that the transport costs estimated for Sardinia are downward biased since the costs of sea or air transport are always higher than those of land transport, the above discussion is reasonably acceptable, thus the proposed approach represents a good starting point that can be easily modified and adapted to other case studies.

Note that calculating the actual additional cost of insularity is not the main goal of this paper. We aim to show that insularity represents an additional limit for the retail sector, and we use Sardinia and Esselunga as a useful example. The impossibility for a retailer such as Esselunga (who uses distribution centres and might be interested in exploiting economies of density) to place a distribution centre or additional stores between, for example, Lazio and Sardinia, represents the additional challenge faced by Esselunga. In this regard, distance includes the actual kilometres between Sardinia and the mainland, but also the fact that in the space between Sardinia and the mainland no stores or distribution centres can be placed, thus breaking the distribution network.

Third, the solution to the Esselunga problem allow one to disentangle insularity from peripherality. Since the distribution costs are proportional to the distance between the stores and the nearest distribution centre, we will focus on the average of the distances, $\bar{D}$. The reduction in the distance from distribution centres is huge in relatively central regions located on the mainland (i.e., Lazio) as well as in peripheral regions (i.e., Calabria). In Lazio, the average distance shifts from 251.040 to $69.782 \mathrm{~km}$; in Calabria it decreases from 678.06 (2013) to $92.98 \mathrm{~km}$ (2035); while in Sardinia it moves from 481.467 to $362.874 \mathrm{~km}$, as described in Table 2. This allows one to disentangle insularity from peripherality and peripheral areas. ${ }^{23}$ The additional specific burden sustained by the islands is higher than that sustained by peripheral regions.

Furthermore, the additional specific burden sustained by the islands is higher than that sustained by them when connected to the mainland. In fact, there are important differences when looking at Sicily and Sardinia. They are both islands, although Sardinia is more remote (i.e., located far from the mainland) and less connected with the 
mainland compared with Sicily. In this regard, in Sicily the average distance moves from 758.739 to $128.431 \mathrm{~km}$, while in Sardinia the average distance decreases from 481.467 to $362.874 \mathrm{~km}$ (Table 2).

In symmetry with the real case, we studied the diffusion of Esselunga in a period equal to 33 years, hypothesizing the opening of 127 stores in five regions. However, the assumptions we made do not affect the results. A retailer who wishes to extend its store network will obviously also evaluate the possibility of locating stores in the other Italian regions such as Abruzzo, Basilicata, Molise and Puglia. When considering only land transport, that is, the standard Esselunga mode of transport, a distribution centre on an island only serves the stores located in that island, while the distribution centres located on the mainland - though in a peripheral region - also serve stores in the other regions. This naturally implies a bigger logistic network for the distribution centres on the mainland, but also a market share for the stores on the mainland bigger than the one of the distribution centres and the stores on an island. As a result, the retailer will place stores in Abruzzo, Basilicata, Molise and Puglia first, and then in Sardinia.

This supports the statement that placing stores on the mainland is more convenient first of all and thus strengthens the validity of our results and considerations.

\section{CONCLUSIONS}

The islands' permanent geographical features such as smallness, remoteness and vulnerability have made it necessary to explore the additional challenges that insularity poses for economic development, focusing on the islands' peculiarity compared with similar territories such as peripheral and remote areas.

Considering the growing recognition by researchers and policy-makers of the significant economic disadvantage faced by the islands, this paper focuses on the relatively unexplored challenges generated by insularity from a novel viewpoint, disentangling insularity from peripherality and remoteness.

We used a multidisciplinary approach, including statistical-econometric and modelling-simulation methods, to investigate and quantify the additional burden that this permanent geographical condition poses for an Italian retailer, Esselunga, that wants to expand its network throughout the entire Italian territory, relying on the economies of density.

The quantitative analysis shows that land discontinuity has a strong negative effect on the profit of a retailer who relies on the economies of density, so that placing stores on an island implies an additional cost.

We found that placing stores on an island represents the least profitable choice. The distance between stores and distribution centres for the regions on the mainland shows a remarkable decrease as the network increases (i.e., distribution centres are opened), whereas this distance on an island does not follow such a pattern. Given that the distribution costs are proportional to this distance, a retailer that decides to open stores on an island first, and then to expand onto the mainland, would not benefit from the lower distribution costs entailed by the economies of density, thus getting lower profits.

Note that although this work considers a specific case study, the proposed approach can be applied to any store network that relies on the economies of density and spreads on a territory composed of a mainland and one or more islands.

The model has some limitations. First, the results are based on the model calibration. The main variables affecting the results are the measure of cost per kilometre, $\tau$, whose impact has been discussed above, and the variables used to estimate sales in stores. Specifically, the profitability of a store depends on the estimated demand, the distribution costs, and also on the potential consumers, which in turn depend on the number of municipalities in the network.

The estimate of demand shows results similar to those estimated by Holmes for the Walmart network, despite the limited number of stores in the Esselunga network.

For example, we found that more competitors in a densely populated area decrease the probability of buying from an Esselunga store, while distant stores are less attractive. Furthermore, being a large store (in terms of square metres and number of employees) increases the attractiveness of Esselunga, as well as the presence of parking facilities (see Appendix B in the supplemental data online for more details). Additionally, distribution costs play a key role in the profit-maximizing algorithm, hence in the choice of the intertemporal openings sequence. As an example, opening first in Lazio and then in Campania is a profit-maximizing choice, even if stores in Campania have a higher population density than those in Lazio (see Table D4 in Appendix D in the supplemental data online). Opening stores in Campania would indeed break the network contiguity, leading to higher distribution costs and thus lower profits than those that could be obtained opening in Campania. Furthermore, the sensitivity of consumers' choices to distance has not been introduced explicitly though a distance-decay function, but only indirectly through the demand model, which in turns affects the consumers' decision to buy in a certain store (location). The availability of real data on the actual transport network would have allowed a better characterization of proximity to demand. However, it is likely that the marginal impact of proximity to demand in affecting consumers' choices (i.e., the decision to buy in a store), once controlling for location (spending capacity, density) and store-specific ones (e.g., parking availability), is not so high.

Lastly, our model might underestimate the number of potential customers and thus the potential revenue of each store. It does not take into account all the Italian municipalities, but only a restricted sample. This would imply that, in reality, a higher number of municipalities would be located close to the store, thus raising the number of potential consumers.

Nevertheless, the model is fairly robust and this underestimation does not affect the main results. Even if we considered all the Italian municipalities, the number of 
potential consumers of Sardinian stores would be lower than the potential consumers of the stores placed on the mainland. The market size of the stores placed on the mainland is certainly bigger than that of Sardinian stores and, as already mentioned, only when the market on the mainland is saturated will the retailer find it convenient to place new stores and distribution centres in Sardinia.

The results suggest some interesting policy implications. Island discontinuity with respect to the mainland cannot be eliminated, but only offset with adequate custom-tailored policy interventions, which would take the peculiarity of the insularity condition into proper account. In other words, bad geography cannot be overcome, whereas the condition of isolation can. Art. 174 of TFUE (Trattato sul funzionamento dell'Unione europea) recognizes insularity as a structural disadvantage; however, it does not identify specific policies to mitigate this condition, leaving a substantial burden of uncertainty on which policies would be effective, and feasible. The present work contributes to the identification of the additional costs and disadvantages related to insularity - specifically those arising from the lower profits for retailers and lower consumer welfare - suggesting potential directions to design effective and feasible policy measures.

Specifically, it shows that being insular implies additional costs (besides those associated with remoteness) for businesses that exploit economies of density. Being a non-connected node prevents a distribution chain such as the retailer Esselunga from fully exploiting the benefits of economies of density, significantly affecting profitability and, in turn, consumers' welfare.

\section{ACKNOWLEDGEMENTS}

The authors thank Fabiano Schivardi and Concetta Rau for useful suggestions made during the early stages of this research project.

\section{DISCLOSURE STATEMENT}

No potential conflict of interest was reported by the authors.

\section{FUNDING}

The authors acknowledge financial support from the Regione Autonoma della Sardegna (L.R. 7/2007 - project Monetary and Non Monetary Costs of Insularity: Measuring Issues and Policy Implications). The funding source has no involvement in any phase of the research.

\section{NOTES}

1. For example, this refers to key development indicators, such as gross domestic product (GDP) per capita, migratory balance, unemployment rate, educational attainment, research and development (Spilanis, Kizos, Vaitis, \& Koukourouvli, 2013; ESPON, 2010).
2. Licio and Pinna (2013), in this regard, have noticed that distance and discontinuity are interconnected dimensions that contribute to define three distinct groups of islands characterized by different degrees of insularity: fully insular (island states), partially insular and non-insular countries.

3. For more details, see Krugman (1991), Venables (1996), Ottaviano and Thisse (2005), and Ottaviano, Tabuchi, and Thisse (2002).

4. Smallness is a reinforcing condition to remoteness. Small islands might face higher transport costs compared with larger islands due to the reliance on small and fragmented cargoes or the exclusion from major sea and air transport and the consequent delays (Briguglio, 1995).

5. Empirical papers investigating the effect of insularity on economic development provide mixed evidence (Armstrong \& Read, 1998, 2004; Armstrong, Ballas, \& Staines, 2006; Bertram \& Karagedikli, 2004), while the theoretical models (i.e., New Economic Geography) investigate the role of smallness and peripherality without explicitly handling the distinctive features of the island economies and their consequences in terms of firm localization and performance (Krugman, 1991; Ottaviano et al., 2002; Ottaviano \& Thisse, 2005).

6. The fact that in reality Esselunga does not exploit economies of density (see the analysis of the Esselunga real network in Appendix $\mathrm{C}$ in the supplemental data online) might be due to management or administrative/ political constraints (i.e., political barriers that prevented Esselunga from opening new stores below EmiliaRomagna). However, this is not significant to the present analysis.

7. Among the most relevant contributions, see Krugman (1991), Ottaviano et al. (2002), and Ottaviano and Thisse (2005) as well as the recent contribution of Allen and Arkolakis (2014) that emphasizes the role of remoteness and thus trade (trade over space is costly) in determining disparities of economic development over time.

8. Pinna and Licio (2013) measure different states of insularity (considered as a 'state of nature'), finding that island states have a worse performance than countries with islands.

9. Klaesson and Öner (2014) provide a detailed literature review on this topic.

10. According to the McKinsey Global Institute (2001), Walmart alone is responsible for a large aggregate productivity gain realized over the past quarter century.

11. Following Holmes (2011), and in the absence of any prior knowledge and not having access to more detailed data for the estimation of transport costs, we assumed a linear relationship for simplicity.

12. Due to data limitations, the analysis assumed amortization cost to be a linear function of revenues. We did not model the new stores opening as a function of the previous stores' full capacity.

13. We explored the sensitivity of the results using alternative radii, specifically 25 and $35 \mathrm{~km}$. We eventually found that the opening sequence remains the same. The greater the radius, the lower is the sensibility of the 
model because this radius selects the potential consumers of a store and then, through the probability $p(t)_{j, l}$, the number of potential consumers decreases as we move towards greater densities and distances, thus capturing the negative effect of population density and distance on demand.

14. The variable dist ${ }_{j l}$ is distance $(\mathrm{km})$ between store location $j$ and location $l$.

15. This is because a consumer at location $l$ usually buys at a store located near their house rather than at a more distant similar store. The term $t_{O, j}<t_{O, j^{\prime} \in l}$ indicates that the opening date $t_{O, j}$ of store $j$ is earlier with respect to that of store $j^{\prime}, t_{O, j^{\prime}}$.

16. This probability captures indirectly the effects of distance decay and depends on the distance between location $\boldsymbol{l}$ and store $\boldsymbol{j}$ and on the population density of municipality $l$.

17. As in Holmes (2011), the formulation of the demand model takes prices as given and does not consider strategic and dynamic interactions between Esselunga and its competitors, since this is not the purpose of this paper. While such a specification might not encompass all the factors affecting the choice of the store location, this is unlikely to affect the results.

18. Estimating the degree of market overlap precisely is beyond the purpose of this paper, and the cannibalization phenomenon due to the Esselunga competitors is taken into account in the demand model.

19. Esselunga did not follow the economies of density in its real diffusion, as illustrated in detail in Appendix $\mathrm{C}$ in the supplemental data online, so the analysis reported in this section concerns only the hypothetical network.

20. The estimation of the degree of market overlap is beyond the scope of this paper. Thus, the results represents a rough estimate.

21. The year 2013 is when the hypothetical diffusion of Esselunga starts, while 2020, 2027 and 2035 are when new distribution centres at Sala Consilina, Latina and Messina respectively open. These are the years when the distance between store $\boldsymbol{j}$ and the distribution centre can vary.

22. $\overline{\boldsymbol{C}}$ is computed as the average of the distance $\bar{D}$ multiplied by parameter $\boldsymbol{\tau}$, which is $€ 2805$ per kilometre per year.

23. From an economic perspective, peripherality and insularity impact the demand model differently due to the wealth of the inhabitants. In the demand model the different wealth of the inhabitants enters through the variable $g d p$, which represents the regional-level GDP per capita (see equations 3-5 in Appendix B in the supplemental data online). In addition, in our specific case study, the Italian context, there is a socioeconomic gap between South and North which is stronger than the peripherality-insularity gap. In other terms, Italian islands are similar, in terms of socioeconomic indicator, to the southern regions. In the analysis, we control for crossregional differences in household spending capacity controlling for regional-level GDP per capita (see the value of $g d p$ in Table D4 in Appendix D in the supplemental data online).

\section{ORCID}

Luisanna Cocco (D) http://orcid.org/0000-0002-5055-9166 Manuela Deidda (D) https://orcid.org/0000-0002-09216970

Michele Marchesi (D) https://orcid.org/0000-0003-15408773

\section{REFERENCES}

Allen, T., \& Arkolakis, C. (2014). Trade and the topography of the spatial economy. Quarterly Journal of Economics, 129, 1085-1140. doi:10.1093/qje/qju016

Armstrong, H. W., Ballas, D., \& Staines, A. (2006). A comparative analysis of the economic performance of Greek and British small islands. Paper presented at the 36th Regional Science Association International (British and Irish Section) conference, Jersey, Channel Islands.

Armstrong, H. W., \& Read, R. (1998). Trade and growth in small states: The impact of global trade liberalisation. World Economy, 21, 563-585. doi:10.1111/1467-9701.00148

Armstrong, H. W., \& Read, R. (2004). Insularity, remoteness, mountains and archipelagos: a combination of challenges facing small states? Paper presented for the Regional Studies Association Conference 'Europe at the Margins: EU Regional Policy, Peripherality and Rurality', University of Angers.

Basker, E. (2005). Selling a cheaper mousetrap: Wal-mart's effect on retail prices. Journal of Urban Economics, 58, 203-229. doi:10. 1016/j.jue.2005.03.005

Basker, E., \& Noel, M. (2009). The evolving food chain: Competitive effects of Wal-mart's entry into the supermarket industry. Journal of Economics and Management Strategy, 18, 977-1009. doi:10. 1111/j.1530-9134.2009.00235.x

Bertram, G., \& Karagedikli, X. (2004). Are pacific economies converging or diverging? In J. Poot (Ed.), On the edge of the global economy (pp. 106-122). Cheltenham: Edward Elgar.

Briguglio, L. (1995). Small island developing states and their economic vulnerabilities. World Development, 23(9), 16151632.

Christaller, W. (1933). Die zentralen Orte in Süddeutschland: eine ökonomisch-geographische Untersuchung über die Gesetzmässigkeit der Verbreitung und Entwicklung der Siedlungen mit städtischen Funktionen. Jena: Gustav Fischer.

Cleary, R., \& Lopez, R. (2008). Does the presence of Wal-mart cause Dallas/Fort Worth supermarket milk prices to become more competitive? (Technical Report No. 99). Storrs: Food Marketing Policy Center, University of Connecticut.

Confcommercio. (2014). Analisi e previsioni per il trasporto merci in italia (Technical Report). Ufficio Studi ConfcommercioImprese per l'Italia.

Converse, P. D. (1943). A study of retail trade areas in east central Illinois. University of Illinois.

Deidda, M. (2016). Insularity and economic development: A survey. International Review of Economics, 63(2), 107-128.

Ellickson, P. B., \& Grieco, P. L. (2013). Wal-mart and the geography of grocery retailing. Journal of Urban Economics, 75, 1-14. doi:10.1016/j.jue.2012.09.005

European Small Islands Federation (Eurisles). (2002). Off the coast of Europe: European construction and the problem of the islands, study undertaken by Eurisles on the initiative of the Islands Commission of CPMR (Technical Report).

European Observation Network for Territorial Development and Cohesion (ESPON). (2010). EUROISLANDS - The development of the islands - European islands and Cohesion Policy (Technical 
Interim Report v.3). Retrieved from https://www.espon.eu/ programme/projects/espon-2013/targeted-analyses/euroislandsdevelopment-islands-\%E2\%80\%93-european-islands

Hausman, J., \& Leibtag, E. (2005). CPI bias from supercenters: Does the BLS know that Wal-mart exist? (Working Papers No. 10712). Cambridge, MA: National Bureau of Economic Research (NBER).

Hausman, J., \& Leibtag, E. (2007). Consumer benefits from increased competition in shopping outlets: Measuring the effect of Wal-mart. Journal of Applied Econometrics, 22, 1157-1177. doi:10.1002/jae.994

Holmes, T. J. (2011). The diffusion of Wal-mart and economies of density. Econometrica, 79(1), 253-302. doi:10.3982/ECTA7699

Holmes, T. J., \& Lee, S. (2012). Economies of density versus natural advantage: Crop choice on the back forty. Review of Economics and Statistics, 94(1), 1-19. doi:10.1162/REST_a 00149

Klaesson, J., \& Öner, Ö. (2014). Market reach for retail services. Review of Regional Studies, 44(2), 153-176.

Krugman, P. R. (1991). Geography and trade. Cambridge, MA: MIT Press.

Licio, V. M., \& Pinna, A. M. (2013). Measuring insularity as a state of nature: Is there a case of bad geography? (Technical Report, Centre for North South Economic Research (CRENoS) Working Papers No. 2013/22 ). Cagliari: University of Cagliari.

Lösch, A. (1944). Die räumliche ordnung der wirtschaft. Jena: Gustav Fischer.

Mazzarino, M. (1998). Intermodalitá e trasporto combinato Lineamenti teorici ed operativi (I Quaderni di Trasporti Europei). Trieste: ISTIEE.

McKinsey Global Institute. (2001). U.S. productivity growth 19952000: Understanding the contribution of information technology relative to other factors. Washington, DC: McKinsey Global Institute.
Neumark, D., Zhang, J., \& Ciccarella, S. (2008). The effects of Walmart on local labor markets. Journal of Urban Economics, 63(2), 405-430. doi:10.1016/j.jue.2007.07.004

O'Kelly, M. E. (1981). A model of the demand for retail facilities, incorporating multistop, multipurpose trips. Geographical Analysis, 2, 134-148.

Ottaviano, G. I., Tabuchi, T., \& Thisse, J. F. (2002). Agglomeration and trade revisited. International Economic Review, 43, 409-435. doi:10.1111/1468-2354.t01-1-00021

Ottaviano, G. I., \& Thisse, J.-F. (2005). New Economic Geography: What about the N? Environment and Planning A, 37, 1707-1725. doi:10.1068/a3730

Pinna, A., \& Licio, V. (2013). Measuring insularity as a state of nature. is there a case of bad geography? ERSA Conference Papers (No. ersa13p706). European Regional Science Association (ERSA).

Reilly, W. J. (1953). The law of retail gravitation, 2nd ed. New York: Pilsbury.

Rouse, J. W. (1953). Estimating productivity for planned regional shopping centers, news and trends in city development. Washington, DC: Urban Land Institute.

Spilanis, I., Kizos, T., Vaitis, M., \& Koukourouvli, N. (2013). Measuring the economic, social and environmental performance of European island regions: Emerging issues for European and regional policy. European Planning Studies, 21, 1998-2019. doi:10.1080/09654313.2012.722970

Thill, J.-C., \& Thomas, I. (1987). Toward conceptualizing tripchaining behavior: A review. Geographical Analysis, 1, 1-17.

Venables, A. J. (1996). Equilibrium locations of vertically linked industries. International Economic Review, 37, 341-359. doi:10. 2307/2527327

Zagari, C. (2011). Semestre Europeo n. 1 - Anno 1, Luglio 2010: Rivista europea di best practices. Opere varie. Gangemi. 